\title{
Effects of dietary milk- and soya-phospholipids on lipid-parameters and other risk indicators for cardiovascular diseases in overweight or obese men - two double-blind, randomised, controlled, clinical trials
}

\author{
Anne Weiland, Achim Bub, Stephan W. Barth, Juergen Schrezenmeir† and Maria Pfeuffer* \\ Department of Physiology and Biochemistry of Nutrition, Max Rubner-Institut, Haid-und-Neu-Strasse 9, D-76131 Karlsrube, Germany
}

(Received 6 January 2016 - Final revision received 22 February 2016 - Accepted 3 March 2016)

Journal of Nutritional Science (2016), vol. 5, e21, page 1 of 9

doi:10.1017/jns.2016.9

\section{Abstract}

The present study examined the effect of milk phospholipids (milk-PL) on lipid metabolism and on other risk factors for CVD, in comparison with milk fat (control) or soya phospholipids (soya-PL), respectively. Two double-blind parallel-group intervention trials were conducted in overweight or obese male subjects. In the first trial (trial 1), sixty-two men consumed milk enriched with either $2 \mathrm{~g}$ milk-PL or $2 \mathrm{~g}$ milk fat (control) for 8 weeks. In trial 2 , fifty-seven men consumed milk enriched with either $3 \mathrm{~g}$ milk-PL or $2.8 \mathrm{~g}$ soya-PL for 7 weeks. In trial 1, milk-PL as compared with control reduced waist circumference but did not affect plasma lipids (total, HDL- and LDL-cholesterol, total cholesterol:HDL-cholesterol ratio, TAG, phospholipids), apoB, apoA1, glucose, insulin, insulin sensitivity index, C-reactive protein, IL-6, soluble intracellular adhesion molecule and total homocysteine (tHcy). Serum activities of alanine transaminase and aspartate transaminase were not changed. Activity of $\gamma$-glutamyl transferase (GGT), a marker of fatty liver, increased in the control but not in the milk-PL group, with a significant intervention effect. In trial 2, milk-PL as compared with soya-PL did not affect the above-mentioned parameters, but decreased GGT. Subjects with the methylenetetrahydrofolate reductase mutations CT and TT had $11 \%(P<0 \cdot 05)$ higher baseline tHcy concentrations than those with the wild-type CC. However, genotype did not modulate the phospholipid intervention effect on tHcy. In conclusion, supplementation with milk-PL as compared with control fat reduced waist circumference and, as compared with both control fat and soya-PL, GGT activity.

Key words: Milk phospholipids: Soya phospholipids: Plasma lipids: Human nutrition: CVD

A high cholesterol concentration, particularly in LDL, and a low HDL-cholesterol (HDL-C) concentration are accepted risk factors for CVD. Obesity, particularly abdominal obesity, is an independent risk factor for CHD in middle-aged men ${ }^{(1,2)}$. Obesity promotes alterations in other intermediate risks such as dyslipidaemia, glucose intolerance and inflammatory state $^{(2)}$. Non-alcoholic fatty liver disease promoted by obesity is also associated with an increased prevalence of $\mathrm{CVD}^{(3,4)}$.

Phospholipids (PL) belong to the dietary components which may affect cholesterol metabolism. They are polar lipids which occur in all animal and plant membrane structures. The human diet provides 2-8 $\mathrm{g}$ PL per d, which represents $1-10 \%$ of total fat intake. Foods with a high PL content include eggs, meats, fish, grains and oilseeds. The most common PL in foods is phosphatidylcholine (PC). Sphingomyelin (SM), a P-containing sphingolipid, is solely present in animal food sources, i.e. in eggs, meat and fish, and is ingested at a level of $0 \cdot 3-0 \cdot 4 \mathrm{~g} / \mathrm{d}^{(5)}$.

Previously mostly soya-PL (trivial name soyabean lecithin) were tested in the course of animal and human feeding trials. They are rich in PUFA, mainly linoleic acid. In animal studies

\footnotetext{
Abbreviations: ALT, alanine transaminase; AST, aspartate transaminase; CRP, C-reactive protein; GGT, $\gamma$-glutamyl transferase; HDL-C, HDL-cholesterol; HOMA-IR, homeostasis model assessment of insulin resistance; LDL-C, LDL-cholesterol; MFGM, milk fat globule membrane; MTHFR, methylenetetrahydrofolate reductase; PC, phosphatidylcholine; PL, phospholipid; SM, sphingomyelin; TC, total cholesterol; tHcy, total homocysteine.
}

* Corresponding author: M. Pfeuffer, fax +49 7216625 404, email maria.pfeuffer@mri.bund.de

† Present address: Clinical Research Center, Schauenburgerstrasse 116, D-24118 Kiel, Germany.

(C) The Author(s) 2016. This is an Open Access article, distributed under the terms of the Creative Commons Attribution licence (http://creativecommons.org/licenses/by/4.0/), which permits unrestricted re-use, distribution, and reproduction in any medium, provided the original work is properly cited. 
soya-PL inhibited cholesterol absorption, decreased plasma cholesterol and also liver lipids, and protected against the development of atherosclerosis (for a review, see Cohn et $\left.a l^{(5)}\right)$. Small-size short-term human studies showed that soya-PL may increase HDL-C ${ }^{(6)}$ and apoA $1^{(6,7)}$.

Animal polar lipids differ from soya-PL in several aspects. Only animal PL contain SM. Particularly their PC and SM classes are rich in SFA. The majority of milk polar lipids, mostly PL (milk-PL), are contained in the milk fat globule membrane $(\mathrm{MFGM})^{(8)}$ and are closely associated with proteins ${ }^{(9)}$. In fact, animal-source PL or 'saturated' PL showed high bioactivity. Milk-SM inhibited cholesterol absorption in mice more than egg-PC, despite a similar fatty acid pattern ${ }^{(10)}$. Milk-PL at a dose of 0.5 or $1.2 \%$ decreased plasma cholesterol in mice on a high-fat diet ${ }^{(11,12)}$ but not on a regular-fat chow diet ${ }^{(11)}$. Recently published well-designed human studies found no effect of milk-PL on plasma lipids ${ }^{(13,14)}$, but a significant effect of PL-rich buttermilk ${ }^{(15)}$, a favourable trend of buttermilk combined with egg yolk as compared with egg alone $^{(16)}$, and of milk fat with intact MFGM as compared with pure milk fat ${ }^{(17)}$.

Metabolic effects of PL go beyond those on cholesterol absorption and plasma lipids (for a review, see Kullenberg et al. $\left.{ }^{(18)}\right)$. In mouse or rat experimental models, soya-PL ${ }^{(19)}$, as well as milk-PL ${ }^{(11,12,20)}$ and $\mathrm{SM}^{(21)}$ decreased liver lipids. An SM-supplemented diet increased hepatic gene expression of PPAR $\alpha$, and decreased expression of stearoyl-CoA desaturase-1 (SCD1) in Zucker fatty rats ${ }^{(21)}$. Also, mice on a high-fat milk-PL-enriched diet showed reduced hepatic expression of SCD1 and fatty acid synthase genes ${ }^{(11)}$. Lower SCD1 activity is linked to improved liver lipid metabolism and insulin sensitivity ${ }^{(22)}$.

PC and SM are important dietary sources of choline. The European Food Safety Authority has approved claims for dietary choline with respect to lipid metabolism, liver function and homocysteine (Hcy) metabolism ${ }^{(23)}$. The Institute of Medicine considers $550 \mathrm{mg} / \mathrm{d}$ choline as adequate intake for men ${ }^{(24)}$. Most subjects on an experimental choline-deficient diet developed fatty liver, experienced muscle damage, or both, within a few weeks ${ }^{(25)}$. Choline metabolism, methionine metabolism and folate metabolism are interrelated. The dietary requirement for choline varies substantially among individuals, and is modulated by SNP in genes of choline and folate metabolism ${ }^{(26)}$, including methylenetetrahydrofolate reductase (MTHFR $^{(27,28)}$.

Based on the hypothesis that PL are relevant for the beneficial health effects of dairy products ${ }^{(29)}$, we studied the metabolic effects of milk-PL. The first study assessed the metabolic effects of milk-PL as compared with the same amount and pattern of fatty acids provided as milk fat. In a second step the effects of milk-PL were compared with those of soya-PL, i.e. PL with both a different PL class pattern and a different fatty acid pattern. The main focus of these studies was on the treatment effects on the total cholesterol (TC): HDL-C ratio. The TC:HDL-C ratio allows the best prediction of future coronary events, closely followed by the apoB:apoA1 ratio $^{(30)}$. In order to cover further parameters relevant to CVD risk, plasma parameters of lipid and carbohydrate metabolism, various inflammation markers, total Hcy (tHcy) and liver enzyme activities were measured. Furthermore, the polymorphism MTHFR 677, which may affect choline and betaine metabolism, respectively, was determined, as a potential genetic determinant affecting PL bioactivity.

\section{Subjects and methods}

\section{Subjects}

Participants were recruited through the Max Rubner-Institut database and local advertisements in Karlsruhe and the surrounding area, Germany. Men were eligible if between 50 and 76 years of age, overweight $\left(B M I \geq 27 \mathrm{~kg} / \mathrm{m}^{2}\right)$ and nonsmokers. Exclusion criteria for both trials were the use of drugs affecting lipid metabolism, acute or chronic gastrointestinal diseases (e.g. diseases affecting nutrient absorption, digestion, metabolism or excretion), diabetes (fasting glucose $\geq 7 \cdot 0$ $\mathrm{mmol} / \mathrm{l})$, milk protein allergy or lactose intolerance, and furthermore soya protein allergy in trial 2 . The studies were conducted according to the guidelines laid down in the Declaration of Helsinki and all procedures involving human subjects were approved by the ethics committee of the State Medical Chamber of Baden-Württemberg (F 2010-020 and F 2010-089). Written informed consent was obtained from all subjects prior to the studies. The studies were registered at https://drks-neu.uniklinik-freiburg.de/drks_web as DRKS00000383 (trial 1) and DRKS00003125 (trial 2). Participants were asked to consume no more than one alcoholic drink per $\mathrm{d}$, and not to change their eating habits and physical activity routine during the trials. The use of supplemental vitamins, minerals, phytochemicals or $n-3$ oil supplements was forbidden. A list of products which should be avoided was provided. The subjects were requested to inform the study physician about any newly prescribed medications.

\section{Test materials}

Milk-PL preparations (Lipamin M20; Lecico) were isolated from butter serum. PL were quantified by ${ }^{31} \mathrm{P}-\mathrm{NMR}$-spectroscopy (Spectral Service). The Lipamin M20 lot used for trial 1 contained $18.4 \%$ PL, 31.6\% total fat, $51.6 \%$ protein and $5.4 \%$ lactose. The lot used for trial 2 contained $31.2 \%$ PL, 41.2 $\%$ total fat, $46.0 \%$ protein and $1.2 \%$ lactose. PC and SM represented 29.2 and $23.1 \%$ of total PL in the lot for trial 1 and 29.5 and $25.1 \%$ in the lot for trial 2. The soya-PL preparation (deoiled soya lecithin P 900 IPM; Lecico) used for trial 2 contained $91 \%$ total fat and $72 \%$ PL according to the manufacturer, but only $66.1 \% \mathrm{PL}$ as later determined by ${ }^{31}$ P-NMR-spectroscopy. PC represented $34.7 \%$ of the total soya-PL.

\section{Study design trial 1}

This trial was performed in spring 2010 in a randomised, double-blind and parallel design. Eligible participants were randomly assigned following simple randomisation procedures (computerised random numbers between 0 and 1) to one of 
two treatment groups. In all, seventy-six men were screened for participation; sixty-three were included in the study. One dropped out when he started to use non-permitted medication, so sixty-two men completed the trial. During the 8 -week intervention the participants consumed daily $200 \mathrm{ml}$ of PL-enriched drink (containing $2 \mathrm{~g}$ milk-PL) or $200 \mathrm{ml}$ of control drink (containing $2 \mathrm{~g}$ milk fat). The PL-drink was semi-skimmed milk (1.5\% fat) supplemented with $5.4 \%$ Lipamin M20 powder (Lecico). To make up for protein, lactose and lipids of the Lipamin M20 powder, the control drink was prepared by enriching semi-skimmed milk with cream and skimmed milk concentrate. Composition of both test drinks is described in Table 1 . They were manufactured and bottled in enhanced shelf-life quality packaging (Unternehmensgruppe Theo Müller). Fresh batches were provided and picked up by the participants every 2 weeks. Drinks were stored refrigerated until consumption. Appearance, taste and packaging of the drinks were identical and bottles $(200 \mathrm{ml}$ volume) were coded in such a way that participants and staff were unaware of the drink allocation. Participants were asked to consume the drinks with a meal.

\section{Study design trial 2}

This trial was performed in spring 2011. Of the seventy-one men screened for participation, fifty-eight were included in the study. One man in the milk-PL group dropped out because of suspected allergic reactions, so fifty-seven men completed the trial. Thirty-eight of these men also had participated in trial 1. During the 7 -week intervention the participants consumed daily $250 \mathrm{ml}$ of test drink that provided

Table 1. Composition of the test drinks*

\begin{tabular}{|c|c|c|c|c|}
\hline \multirow[b]{3}{*}{$\begin{array}{l}\text { Milk ( } 1.5 \% \text { fat) } \\
\text { supplemented } \\
\text { with... }\end{array}$} & \multicolumn{2}{|c|}{ Trial 1} & \multicolumn{2}{|c|}{ Trial 2} \\
\hline & Control & Milk-PL & Soya-PL & Milk-PL \\
\hline & $\begin{array}{c}\text { Cream } 4.7 \\
\%, \text { SMC } \\
(10.6 \%) \dagger\end{array}$ & $\begin{array}{l}\text { Lipamin } \\
\text { M20 } \\
(5.4 \%) \ddagger\end{array}$ & $\begin{array}{c}\text { P } 900 \\
\text { IBM } \\
(1.67 \%)\end{array}$ & $\begin{array}{c}\text { Lipamin } \\
\text { M20 } \\
(3.85 \%) \ddagger\end{array}$ \\
\hline \multicolumn{5}{|c|}{ Chemical composition } \\
\hline Fat $(\%)$ & 3.4 & $3 \cdot 2$ & 2.5 & $2 \cdot 6$ \\
\hline Protein (\%) & 4.3 & 5.7 & 3.4 & 5.0 \\
\hline Lactose $(\%)$ & $6 \cdot 2$ & $4 \cdot 8$ & 4.4 & 4.5 \\
\hline DM (\%) & 14.6 & 14.9 & 11.7 & 13.7 \\
\hline Ca (\%) & 0.186 & 0.173 & 0.123 & 0.137 \\
\hline \multicolumn{5}{|c|}{ Absolute amounts provided per $d$ with the test drinks } \\
\hline Volume $(\mathrm{ml})$ & 200 & 200 & 250 & 250 \\
\hline Fat $(\mathrm{g})$ & $6 \cdot 8$ & 6.4 & $6 \cdot 3$ & 6.4 \\
\hline $\mathrm{PL}(\mathrm{g}) \S$ & 0.0 & $2 \cdot 0$ & $2 \cdot 8$ & 3.0 \\
\hline Choline $(\mathrm{mg}) \S \|$ & 0 & 164 & 156 & 264 \\
\hline Energy $(\mathrm{kJ})$ ๆ & 623 & 604 & 577 & 659 \\
\hline
\end{tabular}

PL, phospholipid; SMC, skimmed milk concentrate.

* Chemical analysis was done after blending the carrier milk with supplements. For trial 1 , values are the mean of four batches, each determined in triplicate.

† Cream with $39 \%$ fat and SMC with $35 \%$ DM, $0.26 \%$ fat.

¥ Lipamin M20 lot 1 and lot 2, respectively.

$\S$ Values for supplements only. Concentrations in the milk used for the test drinks (approximately $0.029 \mathrm{~g} / 100 \mathrm{~g} \mathrm{PL}$ and $16.1 \mathrm{mg} / 100 \mathrm{~g}$ choline) not included.

|l Choline supply is calculated from phosphatidylcholine and sphingomyelin concentrations in the supplements.

I) Calculated value. either $3 \mathrm{~g}$ milk-PL or $2.8 \mathrm{~g}$ soya-PL. The drink was semiskimmed milk (1.5\% fat) supplemented with $3.85 \%$ Lipamin M20 powder or $1.67 \%$ soya lecithin (P 900 IBM) (both Lecico). Calculation of the soya-PL supplemental dose was based on the manufacturers' data, to yield $3 \mathrm{~g}$ per 250 $\mathrm{ml}$. However, based on the ${ }^{31} \mathrm{P}-\mathrm{NMR}$-spectroscopy data, the final PL concentration was somewhat lower, namely $2.8 \mathrm{~g}$ per $250 \mathrm{ml}$. Milk drinks for this study were manufactured and bottled in ultra-high temperature treatment (UHT) quality packaging (Milchwerke Mittelelbe) and handed out to the participants at the start of the trial. Drinks were identical in appearance and taste. Bottles ( $250 \mathrm{ml}$ volume) were coded. Again, participants were asked to consume the drinks with a meal.

\section{Diet protocols}

Participants completed 4-d food protocols (according to Koebnick et al. ${ }^{(31)}$, with minor modifications) during and outside the intervention periods. Nutrient intake analysis was done using PRODI 5.7 software and Bundeslebensmittelschlüssel (BLS) version II.3 (trial 1), or Prodi® version 5.9 and BLS version 3.0 (trial 2). Calculation of PL intake was based on recorded food items and PL concentrations reported in the literature. As there were only few data available, the calculated values can give only a rough approximation of the true intake. The USDA nutrient database 2004 for choline (https:// www.ars.usda.gov/SP2UserFiles/Place/80400525/Data/ Choline/Choln02.pdf) was used to estimate choline intake.

\section{Blood sampling}

Fasting venous blood samples were collected before starting the intervention (day zero) and after the intervention, between 07.30 and 10.00 hours. EDTA whole blood (for glutathione determination and DNA preparation), plasma (EDTA, lithium heparin) and serum samples were obtained. When required, samples were stored frozen at $-80^{\circ} \mathrm{C}$ until analysis.

\section{Anthropometric and blood pressure measurements}

Anthropometric measures including waist and hip circumferences and blood pressure measurements were taken at the beginning and at the end of the intervention periods and recorded following standard operation procedures according to WHO $2008^{(32)}$. BMI was calculated by dividing body mass (in kg) by height squared (in $\mathrm{m}$ ). Bioelectrical impedance analysis (SensorMedics) was used to determine percentage of body fat.

\section{Analytical methods}

Fasting plasma or serum samples were analysed for routine clinical parameters as well as concentrations of TAG, TC, HDL-C and LDL-cholesterol (LDL-C), glucose, and $\gamma$-glutamyl transferase (GGT) and aspartate transaminase (AST) activities on the same day by an accredited routine laboratory (MVZ Labor Seelig). ApoA1, apoB and alanine 
transaminase (ALT) activity were assessed enzymatically using the Konelab 20i clinical analyser (Thermo Scientific). Total glutathione in whole blood was measured according to Becker et al. ${ }^{(33)}$. Serum concentrations of insulin and highsensitivity C-reactive protein (CRP) were measured by ELISA (DRG Instruments) as well as soluble intracellular adhesion molecule and IL-6 (R\&D Systems). Serum PL were analysed by an enzymic assay (WAKO Chemicals). Plasma tHcy concentrations were assessed by HPLC with fluorimetric detection according to Toyo'oka \& Imai ${ }^{(34)}$. Homeostasis model assessment of insulin resistance (HOMA-IR) was calculated as ((fasting insulin $\mathrm{mU} / 1 \times$ fasting glucose mmol/1)/22.5) according to Matthews et al. ${ }^{(35)}$. For determination of the MTHFR 677 genotype (rs1801133), peripheral blood mononuclear cell genomic DNA was prepared using a microspin kit (NucleoSpin blood; Macherey-Nagel) and further processed utilising a PCR-based high-resolution

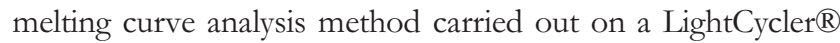
480 instrument with subsequent data processing by gene scanning software (Roche). The respective PCR primer $\left(5^{\prime} \rightarrow 3^{\prime}\right)$ sequences were: (forward) $>>$ ccc aa $\mathrm{ggc}$ cac ccc gaa $\mathrm{gc}<<$ and $>>$ gcc cat gtc ggt gca tgc $\mathrm{ct}<<$ and the according PCR protocol consisted of thirty-nine cycles of denaturation, annealing and extension $\left(95^{\circ} \mathrm{C}, 10 \mathrm{~s} ; 60^{\circ} \mathrm{C}, 15 \mathrm{~s} ; 72^{\circ} \mathrm{C}, 1 \mathrm{~s}\right)$ and a subsequent melting analysis.

\section{Statistical analysis}

A previous study providing 2.8 or $5.8 \mathrm{~g} / \mathrm{d} \mathrm{PL}^{(6)}$ suggested that a PL-induced $6 \%$ decrease in the TC:HDL-C ratio is realistic. Based on another study showing a $0.29 \mathrm{mmol} / 1$ (6.3 \%) decrease in the TC:HDL-C ratio along with a standard deviation of $0.45 \mathrm{mmol} / \mathrm{l}$ in response to dietary modification, and with a baseline TC:HDL-C ratio of $4 \cdot 5^{(36)}$, similar to that in our participants, the required total number of participants completing the study was calculated as $n 58(\alpha=0.05$ two-tailed, power $=90 \%$ ). Data are expressed as mean and standard deviation. Data were tested for normality (ShapiroWilk) and variance homogeneity (Levene). Intervention effects were analysed by repeated-measures ANOVA if datasets were normally distributed and showed variance homogeneity. For datasets with asymmetric distribution delta concentrations

Table 2. Baseline characteristics of the participants (Mean values and standard deviations)

\begin{tabular}{|c|c|c|c|c|}
\hline \multirow[b]{2}{*}{ Variable } & \multicolumn{2}{|c|}{ Trial 1 ( $n$ 62) } & \multicolumn{2}{|c|}{ Trial 2 ( $n 57)$} \\
\hline & Mean & SD & Mean & SD \\
\hline Age (years) & 62.5 & 6.4 & 63.1 & 6.5 \\
\hline Weight (kg) & 94.5 & $10 \cdot 2$ & 93.3 & 9.7 \\
\hline BMI $\left(\mathrm{kg} / \mathrm{m}^{2}\right)$ & $30 \cdot 8$ & 2.4 & 30.4 & 2.4 \\
\hline Waist circumference $(\mathrm{cm})$ & 109.6 & $7 \cdot 2$ & 108.2 & 6.4 \\
\hline Body fat mass (\%) & 31.0 & 2.5 & 31.1 & 2.9 \\
\hline Total cholesterol $(\mathrm{mmol} / \mathrm{l})$ & 5.87 & 0.89 & $5 \cdot 60$ & 0.88 \\
\hline HDL-cholesterol (mmol/l) & 1.37 & 0.34 & 1.31 & 0.30 \\
\hline TAG (mmol/l) & 1.44 & 0.66 & 1.49 & 0.55 \\
\hline Glucose $(\mathrm{mmol} / \mathrm{l})$ & 5.50 & 0.57 & 5.44 & 0.54 \\
\hline ApoA1 (g/l) & 1.60 & 0.23 & 1.62 & 0.21 \\
\hline ApoB (g/l) & 1.27 & 0.25 & 1.37 & 0.21 \\
\hline
\end{tabular}

were compared by $t$ test or Mann-Whitney rank-sum test. Changes of tHcy concentration as a function of MTHFR 677 genotype (CC $v$. CT and T'T combined) were assessed by the Kruskal-Wallis $H$ test. Analyses were carried out using SPSS Inc. PASW 17 software. The level of significance was set at $P<0 \cdot 05$.

\section{Results}

\section{Baseline characteristics}

Baseline characteristics of the participants who completed trials 1 and 2 are presented in Table 2. Participants were either overweight (40.3\% in trial 1 and $56.1 \%$ in trial 2 ) or obese (59.7\% in trial 1 and $43.9 \%$ in trial 2) and all had increased waist circumference, body fat mass and TC concentration. Baseline parameters were not significantly different between the two groups within each trial, and similar between trials 1 and 2 (Table 2). The distribution of the MTHFR 677 genotype in trial 2 was CC ( $n 23 ; 40.4 \%)$, CT $(n 32 ; 56.1 \%)$ and TT (n $2 ; 3.5 \%$ ).

\section{Dietary intake and compliance}

Energy intake and nutrient composition of the habitual diets during the intervention periods of trials 1 and 2 are given in Table 3. Carbohydrate and energy intakes was slightly higher in the soya-PL as compared with the milk-PL group in trial 2 $(P<0 \cdot 05)$. Otherwise there were no differences between intervention groups, and there were no significant differences in energy and nutrient intakes during the intervention and outside the intervention period in both studies. Nutrient intake was comparable with that of the German average population of that age group as assessed in the Nationale Verzehrstudie II (2008) (https://www.bmel.de/SharedDocs/Downloads/Ernaehrung/ NVS_ErgebnisberichtTeil2.pdf?_blob=publicationFile). Major sources of PL in foods were meat and meat products (41.9 and $41.7 \%$, respectively) and egg and egg products $(30.3$ and

Table 3. Energy and nutrient intakes during the intervention periods ${ }^{\star}$ (Mean values and standard deviations of 4-d protocols)

\begin{tabular}{lccccc}
\hline & \multicolumn{2}{c}{ Trial $1(n$ 62) } & & \multicolumn{2}{c}{ Trial 2 $(n$ 57) } \\
\cline { 2 - 3 } \cline { 6 - 7 } & Mean & SD & & Mean & SD \\
\hline Energy $(\mathrm{MJ} / \mathrm{d})$ & 9.49 & 2.18 & & $9.57 \dagger$ & 1.99 \\
Protein $(\%$ energy) & 17.9 & 4.0 & & 17.4 & 4.3 \\
Fat $(\%$ energy) & 36.1 & 11.7 & & 34.98 & 4.8 \\
Carbohydrates $(\%$ energy) & 44.1 & 11.3 & & $45.8 \dagger$ & 9.8 \\
Mono-/disaccharides $(\%$ energy) & 19.6 & 7.6 & & 20.1 & 7.6 \\
Dietary fibre $(\mathrm{g} / \mathrm{d})$ & 27.1 & 8.1 & & 25.4 & 7.8 \\
Cholesterol $(\mathrm{mg} / \mathrm{d})$ & 421 & 152 & & 444 & 227 \\
Ca $(\mathrm{mg} / \mathrm{d})$ & 991 & 332 & & 924 & 270 \\
Vitamin $\mathrm{B}_{6}(\mathrm{mg} / \mathrm{d})$ & 1.9 & 0.5 & 1.9 & 0.5 \\
Folate $(\mu \mathrm{g} / \mathrm{d})$ & 280 & 86 & & 355 & 151 \\
Vitamin $\mathrm{B}_{12}(\mu \mathrm{g} / \mathrm{d})$ & 7.7 & 4.3 & & 8.2 & 7.5 \\
Phospholipids $(\mathrm{g} / \mathrm{d})$ & 3.08 & 1.28 & 3.00 & 1.75 \\
Choline $(\mathrm{mg} / \mathrm{d})$ & 384 & 117 & & 387 & 156 \\
\hline
\end{tabular}

${ }^{*}$ All foods including carrier milk, excluding supplements.

† Energy and carbohydrate intakes were 9.7 and $12 \%$ higher in the soyaphospholipid group as compared with the milk-phospholipid group in trial 2 $(P=0.049$ and 0.035 , respectively). 
$29.2 \%$, respectively). Choline intake was similar to that of US populations ${ }^{(37)}$. Major sources of choline were also meat and meat products (34.3 and $33.0 \%$, respectively) and egg and egg products (18.5 and $17.9 \%$, respectively), closely followed by the food group bread, pastries and grain products (16.6 and $16.4 \%$, respectively).

Participants consumed the test drinks in addition to the normal diet. Test drinks were well tolerated. Subjects did not report side effects, except for one person in trial 2. There were no objective chemical measures (blood parameters) available to assess compliance. But as participants kept in regular contact with the study centre, and on the basis of the dietary records provided, appropriate compliance was assumed.

\section{Intervention effects trial 1}

Milk-PL as compared with control did not change the lipid parameters, namely TC, HDL-C, LDL-C, TAG, PL, the primary parameter TC:HDL-C ratio as well as apoA1 and apoB. Likewise, concentrations of glucose, insulin and HOMA-IR did not change (Table 4). Milk-PL as compared with the control treatment did not change concentrations of CRP, IL-6, soluble intracellular adhesion molecule as well as tHcy (Table 4). Due to technical problems, valid glutathione data were only available at the end of the intervention. Values did not differ between groups ( 0.81 (SD 0.29) v. 0.80 (sD 0.24$) \mathrm{mmol} / \mathrm{l}$ whole blood) for the control and milk-PL groups, respectively. Concerning liver enzyme activities, there were no significant intervention effects on ALT and AST. There was a significant $16 \%$ increase of GGT activity in the control group $(P<0.001)$, but no change in the milk-PL group, and thus a significant intervention effect $(P<0 \cdot 001)$ (Table 4). However, enzyme activities remained in their normal reference ranges. Milk-PL as compared with control fat did not change body weight and BMI during the 8-week intervention. There was a small yet significant decrease in waist circumference.

\section{Intervention effects trial 2}

Milk-PL as compared with soya-PL did not change the lipid parameters, namely TC, HDL-C, LDL-C, TAG, PL, the primary parameter TC:HDL-C ratio as well as apoA1 and apoB. Furthermore, glucose, insulin and HOMA-IR did not change. Of the inflammation parameters, IL- 6 increased in both the milk-PL and soya-PL groups, with no intervention effect. There were no significant changes in CRP, soluble intracellular adhesion molecule, glutathione and tHcy concentrations. Subjects with a mutation in MTHFR 677 (CT and T'T) (thirty-four participants) showed an $11 \%$ higher baseline plasma tHcy concentration than those with the wild-type CC (twenty-three participants) $(P<0 \cdot 05)$. Statistical analysis showed that MTHFR genotype did not modulate the effect of the PL-intervention on plasma tHcy (data not shown). Further, the activity of ALT and AST was also unaffected by intervention. There was a significant intervention effect on GGT activity $(P<0.05)$, in that activity was slightly increased in the soya-PL group and slightly decreased in the
milk-PL group (Table 5). No changes were observed in anthropometric measures and blood pressure.

\section{Discussion}

Milk-PL and soya-PL intakes did not change lipid and apolipoprotein concentrations in our trials. In other well-designed human studies the effect of milk-PL was also moderate or non-existent. The consumption of a drink with $2.8 \mathrm{~g} / \mathrm{d}$ of milk-PL (rich in SM) as compared with a control drink containing the same amount of PL low in SM (66\% egg-PL) for 3 weeks did not significantly change the concentrations of TC, LDL-C, HDL-C, TAG, apoA1 and apoB ${ }^{(14)}$. In subjects with atopic dermatitis, $3 \mathrm{~g} / \mathrm{d}$ milk-PL did not improve TC, LDL-C, HDL-C or TAG ${ }^{(13)}$. In a short pilot study, 1 $\mathrm{g} / \mathrm{d}$ of milk-SM increased HDL-C by approximately $13 \%$, but did not change the TC:HDL-C ratio ${ }^{(38)}$. However, in participants who consumed a drink providing either $45 \mathrm{~g} / \mathrm{d}$ of MFGM-rich buttermilk solids (188 mg/d PL) or $45 \mathrm{~g} / \mathrm{d}$ of a macro-/micronutrient-matched dairy placebo for 4 weeks, the buttermilk as compared with the control drink reduced TC and LDL-C by $3.1 \%$, and TAG by $10.7 \%{ }^{(15)}$. In another study the participants were randomised to one of three dietary regimens, either to no change in the dietary habits (control) or one extra egg per d or $100 \mathrm{ml}$ buttermilk (approximately 90 mg PL per d) together with one egg yolk per d for 12 weeks. In female subjects the regular egg consumption increased TC and LDL-C as compared with the control group, while no such increase was observed in the buttermilk-egg yolk group. Similarly, milk fat with intact MFGM structures $(41.8 \mathrm{~g}$ fat $/ \mathrm{d}, 19.8 \mathrm{mg}$ PL/d) did not increase TC and LDL-C in human subjects, while the same amount of pure butter oil did so. Furthermore, suppression of a number of genes in peripheral blood mononuclear cells was correlated with changes in lipids ${ }^{(17)}$.

Our subjects were somewhat older and more overweight than those of other studies examining the effect of milk-PL ${ }^{(13-17)}$ or pure milk-SM ${ }^{(38)}$, had higher plasma TAG concentrations and somewhat or clearly higher TC:HDL-C ratios. Baumgartner et al. ${ }^{(16)}$ observed a protective effect of milk-PL only in females, but other studies using milk-PL ${ }^{(14,15)}$ or milk-SM ${ }^{(38)}$, as well as studies using soya-PL ${ }^{(6,7,39)}$ gave little indication that males and females respond differently.

Our trials, like two others ${ }^{(13,14)}$, used milk-PL concentrates isolated from butter serum as test material, while again others used buttermilk ${ }^{(15,16)}$ or cream with $\mathrm{MFGM}^{(17)}$. An in vitro precursor study suggested that extensive processing may impair the cholesterol-lowering activity of MFGM from buttermilk, possibly through proteins adsorbing at the surface of MFGM fragments ${ }^{(40)}$. Concentrated isolated MFGM material may thus have differing structural properties than liquid forms in buttermilk or cream, which may in turn affect lipid metabolism differently ${ }^{(41)}$. It is a tempting speculation that this difference in the food matrix may have contributed to the lack of effect in our study and others ${ }^{(13,14)}$. But there is no basis for such an assumption without further appropriate experiments. An alternative explanation would be that other components than PL in buttermilk may contribute to the 
Table 4. Intervention effects of trial 1 (Mean values and standard deviations)

\begin{tabular}{|c|c|c|c|c|c|c|c|c|c|}
\hline & \multicolumn{4}{|c|}{ Control ( $n$ 31) } & \multicolumn{4}{|c|}{ Milk-PL (n 31)† } & \multirow[b]{3}{*}{$P^{\star}$} \\
\hline & \multicolumn{2}{|c|}{ Day 0} & \multicolumn{2}{|c|}{ Day 56} & \multicolumn{2}{|c|}{ Day 0} & \multicolumn{2}{|c|}{ Day 56} & \\
\hline & Mean & SD & Mean & SD & Mean & SD & Mean & SD & \\
\hline \multicolumn{10}{|c|}{ Anthropometric measures and blood pressure } \\
\hline Body weight $(\mathrm{kg})$ & 94.7 & $12 \cdot 6$ & 94.5 & $12 \cdot 2$ & 94.2 & 7.4 & 93.3 & $7 \cdot 7$ & 0.181 \\
\hline $\operatorname{BMI}\left(\mathrm{kg} / \mathrm{m}^{2}\right)$ & $30 \cdot 9$ & 2.9 & 30.8 & $2 \cdot 8$ & 30.7 & 1.9 & $30 \cdot 4$ & $2 \cdot 0$ & 0.138 \\
\hline Waist circumference $(\mathrm{cm})$ & $109 \cdot 0$ & $8 \cdot 1$ & $109 \cdot 1$ & $8 \cdot 3$ & $110 \cdot 2$ & $6 \cdot 1$ & $108 \cdot 8$ & $6 \cdot 2$ & 0.001 \\
\hline Body fat mass (\%) & $30 \cdot 8$ & $2 \cdot 4$ & $30 \cdot 3$ & $2 \cdot 6$ & $31 \cdot 2$ & $2 \cdot 6$ & $30 \cdot 9$ & $2 \cdot 8$ & 0.753 \\
\hline Systolic BP (mmHg) & 131.7 & $17 \cdot 2$ & 131.7 & $16 \cdot 4$ & 139.6 & $21 \cdot 6$ & $135 \cdot 3$ & $19 \cdot 1$ & 0.132 \\
\hline Diastolic BP (mmHg) & 82.7 & 8.9 & $82 \cdot 6$ & 8.9 & 86.4 & $10 \cdot 6$ & 84.0 & $11 \cdot 0$ & 0.174 \\
\hline \multicolumn{10}{|l|}{ Glucose and insulin sensitivity } \\
\hline Glucose $(\mathrm{mmol} / \mathrm{l})$ & 5.51 & 0.47 & 5.35 & 0.43 & 5.49 & 0.66 & 5.42 & 0.63 & 0.334 \\
\hline Insulin (pmol/l) & 104.4 & $51 \cdot 3$ & $107 \cdot 8$ & 98.9 & 89.2 & $52 \cdot 7$ & $92 \cdot 7$ & $54 \cdot 4$ & 0.795 \\
\hline HOMA-IR & 3.74 & 2.03 & 3.74 & 3.72 & 3.20 & 2.06 & $3 \cdot 30$ & $2 \cdot 16$ & 0.495 \\
\hline \multicolumn{10}{|c|}{ Plasma lipids and apolipoproteins } \\
\hline $\mathrm{TC}(\mathrm{mmol} / \mathrm{l})$ & $5 \cdot 70$ & 0.94 & 5.72 & 1.03 & 6.03 & 0.82 & 5.90 & 1.04 & 0.302 \\
\hline LDL-C (mmol/l) & 3.58 & 0.76 & 3.69 & 0.81 & 3.78 & 0.82 & 3.84 & 0.89 & 0.765 \\
\hline $\mathrm{HDL}-\mathrm{C}(\mathrm{mmol} / \mathrm{l})$ & 1.32 & 0.34 & 1.30 & 0.28 & 1.43 & 0.33 & 1.42 & 0.37 & 0.290 \\
\hline TC:HDL-C ratio & 4.50 & 1.05 & 4.56 & 1.20 & 4.46 & $1 \cdot 23$ & 4.40 & 1.22 & 0.533 \\
\hline TAG (mmol/l) & 1.41 & 0.49 & $1 \cdot 70$ & 1.07 & 1.46 & 0.80 & 1.50 & 0.64 & 0.627 \\
\hline $\mathrm{PL}(\mathrm{mmol} / \mathrm{l})$ & 1.88 & 0.26 & 1.93 & 0.37 & 2.03 & 0.32 & 1.97 & 0.32 & 0.091 \\
\hline ApoA1 (g/l) & 1.56 & 0.24 & 1.56 & 0.22 & 1.64 & 0.21 & 1.61 & 0.23 & 0.057 \\
\hline ApoB $(g / l)$ & 1.25 & 0.23 & 1.26 & 0.22 & $1 \cdot 28$ & 0.27 & 1.27 & 0.25 & 0.571 \\
\hline \multicolumn{10}{|c|}{ Biomarkers of inflammation and liver function } \\
\hline CRP (mg/l) & $2 \cdot 19$ & $2 \cdot 32$ & 1.42 & 1.30 & 2.53 & 3.03 & 1.75 & 1.47 & 0.947 \\
\hline sICAM (ng/ml) & $191 \cdot 1$ & 31.5 & 187.6 & 29.1 & 189.9 & $29 \cdot 3$ & 183.6 & $25 \cdot 2$ & 0.426 \\
\hline IL-6 (pg/ml) & 1.62 & 1.48 & $1 \cdot 21$ & 0.43 & 1.34 & 0.77 & $1 \cdot 18$ & 0.54 & 0.134 \\
\hline Homocysteine $(\mu \mathrm{mol} / \mathrm{l})$ & 11.7 & 3.2 & 11.8 & 3.0 & 11.6 & 4.0 & $12 \cdot 0$ & 3.9 & 0.547 \\
\hline $\mathrm{ALT}(\mathrm{U} / \mathrm{l})$ & $18 \cdot 0$ & 8.6 & 20.9 & 10.5 & 17.5 & 9.9 & $17 \cdot 3$ & 7.8 & 0.057 \\
\hline AST (U/l) & $26 \cdot 2$ & $7 \cdot 3$ & $25 \cdot 1$ & $6 \cdot 2$ & $25 \cdot 0$ & $7 \cdot 1$ & 23.5 & $6 \cdot 7$ & 0.296 \\
\hline GGT (U/I) & 37.1 & $16 \cdot 0$ & 43.9 & $22 \cdot 8$ & 34.3 & 15.5 & 33.2 & $14 \cdot 1$ & $<0.001$ \\
\hline
\end{tabular}

Milk-PL, milk phospholipids; BP, blood pressure; HOMA-IR, homeostasis model assessment of insulin resistance; TC, total cholesterol; LDL-C, LDL-cholesterol; HDL-C, HDL-cholesterol; PL, phospholipids; CRP, C-reactive protein; sICAM, soluble intracellular adhesion molecule; ALT, alanine transaminase; AST, aspartate transaminase; GGT, $\gamma$-glutamyl transferase.

* $P$ for intervention effect (time $\times$ group). Parameters were not significantly different between the control and milk-PL groups at the start of the trial. † $n 30$ for IL-6.

effects. Buttermilk is usually fermented and contains lactic acid bacteria. Some of them were reported to affect lipid metabolism $^{(42)}$.

In trial 1 milk-PL reduced waist circumference slightly yet significantly. However, there was no such effect compared with soya-PL in trial 2. Blood pressure did not change in either trial. In the study of Conway et al. ${ }^{(43)}$ a buttermilk supplement reduced systolic blood pressure and also decreased concentration of the angiotensin I-converting enzyme in normotensive subjects. The authors attributed these effects to the proteins of MFGM, as there is evidence that milk peptides can reduce blood pressure (for a review, see Conway et al. ${ }^{(43)}$ ). Beneficial effects of dairy product intake on body weight and body composition are often attributed to the Ca content ${ }^{(44)}$, but also to proteins in milk and milk products ${ }^{(45)}$.

The only parameters of liver function determined in our study were liver enzyme activities in serum. Elevated liver enzyme activities, in particular ALT and GGT, are indicators of fatty liver. We observed a reduced GGT activity in the milk-PL group as compared with the control group in trial 1 , and there was also a reduced activity in the milk-PL group as compared with the soya-PL group in trial 2. Yet all enzyme activities remained within the normal physiological range, and the fatty liver index did not change. ALT, AST or GGT activities were not modified by buttermilk PL in one study ${ }^{(16)}$, or were not examined at all in other studies ${ }^{(13-15,43)}$.

As mentioned before, PL and SM are a source of choline, and may affect liver function also via their role in choline metabolism. As little as $300 \mathrm{mg}$ supplemental choline/d was sufficient to avoid increased serum ALT, AST or GGT activities ${ }^{(28)}$. The majority of our subjects consumed more than this amount. Rat or mouse experiments, which demonstrated decreased AST and ALT activities ${ }^{(19)}$ or decreased liver lipids following a diet with supplemental soya-PL ${ }^{(19)}$, milk-PL ${ }^{(11,12,20)}$ or $\mathrm{SM}^{(21)}$, were performed in animals with enhanced susceptibility due to either genetic disposition ${ }^{(12,21)}$ or diets high in ethanol or fat ${ }^{(11,19,20)}$. Milk-PL supplements had no effects on liver lipids in rats on a normal chow diet ${ }^{(11)}$.

Choline plays a pivotal role as a methyl donor for the remethylation of Hcy to methionine. Moderately elevated concentrations of plasma tHcy have been linked to a variety of disease conditions, including CVD. Higher choline plus betaine intakes (within the normal range) were associated with moderately lower plasma tHcy concentration as well as lower concentrations of inflammatory markers like IL- 6 and TNF- $\alpha$ in an 
Table 5. Intervention effects of trial 2

\begin{tabular}{|c|c|c|c|c|c|c|c|c|c|}
\hline & \multicolumn{4}{|c|}{ Soya-PL (n 29) } & \multicolumn{4}{|c|}{ Milk-PL (n 28) } & \multirow[b]{3}{*}{$P^{\star}$} \\
\hline & \multicolumn{2}{|c|}{ Day 0} & \multicolumn{2}{|c|}{ Day 49} & \multicolumn{2}{|c|}{ Day 0} & \multicolumn{2}{|c|}{ Day 49} & \\
\hline & Mean & SD & Mean & SD & Mean & SD & Mean & SD & \\
\hline \multicolumn{10}{|c|}{ Anthropometric measures and blood pressure } \\
\hline Body weight (kg) & $91 \cdot 0$ & 8.6 & $91 \cdot 1$ & 8.9 & $95 \cdot 6$ & $10 \cdot 4$ & 95.4 & $10 \cdot 3$ & 0.654 \\
\hline BMI $\left(\mathrm{kg} / \mathrm{m}^{2}\right)$ & $30 \cdot 2$ & $2 \cdot 6$ & $30 \cdot 0$ & $2 \cdot 8$ & $30 \cdot 6$ & $2 \cdot 3$ & $30 \cdot 6$ & $2 \cdot 3$ & 0.444 \\
\hline Waist circumference $(\mathrm{cm})$ & $107 \cdot 3$ & $6 \cdot 6$ & $107 \cdot 7$ & $6 \cdot 8$ & $109 \cdot 1$ & $6 \cdot 2$ & 109.4 & $6 \cdot 4$ & 0.816 \\
\hline Body fat mass (\%) & 30.9 & 2.5 & 30.5 & 2.4 & $31 \cdot 2$ & $3 \cdot 3$ & 30.5 & $2 \cdot 8$ & 0.395 \\
\hline Systolic BP (mmHg) & $144 \cdot 1$ & $18 \cdot 6$ & 143.9 & $16 \cdot 6$ & 139.6 & 17.5 & $140 \cdot 1$ & $19 \cdot 8$ & 0.829 \\
\hline Diastolic BP (mmHg) & $91 \cdot 2$ & $8 \cdot 6$ & $91 \cdot 3$ & $7 \cdot 8$ & 91.0 & 11.7 & $92 \cdot 3$ & $12 \cdot 7$ & 0.346 \\
\hline \multicolumn{10}{|l|}{ Glucose and insulin sensitivity } \\
\hline Glucose (mmol/l) & 5.44 & 0.50 & $5 \cdot 33$ & 0.36 & 5.44 & 0.59 & $5 \cdot 20$ & 0.57 & 0.254 \\
\hline Insulin (pmol/l) & 81.9 & $33 \cdot 2$ & 88.8 & $28 \cdot 0$ & 80.5 & $56 \cdot 4$ & $79 \cdot 7$ & $42 \cdot 7$ & 0.609 \\
\hline HOMA-IR & $2 \cdot 89$ & $1 \cdot 27$ & $2 \cdot 75$ & 0.97 & $2 \cdot 77$ & 1.80 & 2.65 & 1.45 & 0.492 \\
\hline \multicolumn{10}{|c|}{ Plasma lipids and apolipoproteins } \\
\hline $\mathrm{TC}(\mathrm{mmol} / \mathrm{l})$ & 5.46 & 0.84 & $5 \cdot 38$ & 0.77 & $5 \cdot 74$ & 0.92 & 5.65 & 1.02 & 0.573 \\
\hline LDL-C (mmol/l) & 3.58 & 0.69 & 3.65 & 0.63 & $3 \cdot 84$ & 0.76 & 3.80 & 0.87 & 0.372 \\
\hline $\mathrm{HDL}-\mathrm{C}(\mathrm{mmol} / \mathrm{l})$ & $1 \cdot 31$ & 0.32 & 1.31 & 0.27 & 1.32 & 0.28 & 1.37 & 0.28 & 0.193 \\
\hline TC:HDL-C ratio & 4.35 & 1.04 & 4.22 & 0.80 & 4.46 & 0.78 & 4.22 & 0.83 & 0.234 \\
\hline TAG (mmol/l) & 1.47 & 0.67 & 1.55 & 0.54 & 1.50 & 0.57 & 1.51 & 0.53 & 0.632 \\
\hline $\mathrm{PL}(\mathrm{mmol} / \mathrm{l})$ & $2 \cdot 19$ & 0.36 & $2 \cdot 22$ & 0.35 & $2 \cdot 24$ & 0.33 & $2 \cdot 27$ & 0.41 & 0.942 \\
\hline ApoA1 (g/l) & 1.61 & 0.22 & 1.59 & 0.20 & 1.63 & 0.20 & 1.63 & 0.22 & 0.516 \\
\hline ApoB (g/l) & 1.33 & 0.22 & 1.35 & 0.20 & 1.41 & 0.20 & 1.38 & 0.25 & 0.249 \\
\hline CRP (mg/l) & 2.43 & 2.09 & $2 \cdot 80$ & 2.75 & 2.62 & 2.59 & $2 \cdot 17$ & 1.70 & 0.576 \\
\hline \multicolumn{10}{|c|}{ Biomarkers of inflammation and liver function } \\
\hline sICAM (ng/ml) & $211 \cdot 2$ & $34 \cdot 8$ & 205.5 & $36 \cdot 7$ & $199 \cdot 3$ & 37.7 & $197 \cdot 3$ & $35 \cdot 1$ & 0.449 \\
\hline IL-6 (pg/ml) & 1.58 & 0.86 & 1.74 & $1 \cdot 16$ & 1.33 & 0.77 & 1.45 & 0.65 & 0.151 \\
\hline Homocysteine $(\mu \mathrm{mol} / \mathrm{l})$ & 13.9 & $5 \cdot 0$ & $13 \cdot 7$ & 4.7 & $12 \cdot 5$ & $4 \cdot 0$ & $12 \cdot 4$ & 3.5 & 0.962 \\
\hline Glutathione (mmol/l WB) & 0.67 & $0 \cdot 13$ & 0.69 & 0.14 & $0 \cdot 70$ & 0.15 & 0.71 & $0 \cdot 16$ & 0.714 \\
\hline $\mathrm{ALT}(\mathrm{U} / \mathrm{l})$ & 13.9 & $5 \cdot 2$ & $15 \cdot 9$ & 6.9 & $12 \cdot 0$ & 4.9 & $13 \cdot 2$ & $6 \cdot 6$ & 0.615 \\
\hline AST (U/I) & $25 \cdot 3$ & 5.5 & $26 \cdot 1$ & $5 \cdot 6$ & 24.9 & $6 \cdot 4$ & $25 \cdot 3$ & 7.9 & 0.442 \\
\hline GGT (U/I) & 36.5 & $15 \cdot 6$ & 37.9 & $16 \cdot 9$ & 33.4 & $15 \cdot 4$ & 32.0 & 13.0 & 0.042 \\
\hline
\end{tabular}

Soya-PL, soyabean phospholipids; milk-PL, milk phospholipids; BP, blood pressure; HOMA-IR, homeostasis model assessment of insulin resistance; TC, total cholesterol; LDL-C, LDL-cholesterol; HDL-C, HDL-cholesterol; PL, phospholipids; CRP, C-reactive protein; sICAM, soluble intracellular adhesion molecule; WB, whole blood; ALT, alanine transaminase; AST, aspartate transaminase; GGT, $\gamma$-glutamyl transferase.

${ }^{*} P$ for intervention effect (time $\times$ group). Parameters were not significantly different between the soya-PL and the milk-PL groups at the start of the trial.

observational study $^{(46)}$. A high choline supplement attenuated the post-methionine load-induced increase in plasma tHcy ${ }^{(28)}$, while a choline-deficient diet increased plasma tHcy ${ }^{(25)}$ '. Participants in our trials had a choline intake comparable with or even higher than the cohort of Detopoulou et al. ${ }^{(46)}$, but intake of PL and choline was highly variable between participants. Considering that also individual requirements are variable $^{(26)}$, it is not surprising that the additional choline provided by the soya-PL or milk-PL supplements did not modify the concentration of tHcy or inflammatory parameters.

MTHFR 677 genotype may modify plasma tHcy. Baseline plasma tHcy concentrations were modestly higher in men with the MTHFR 677T'T relative to men with the 677CC genotype, and increased more strongly in response to low folate intake ${ }^{(27)}$. A post-methionine load-induced increase of plasma tHcy was less pronounced in men with the MTHFR 677 T'T than in those with the 677CC genotype ${ }^{(28)}$. We observed only small yet significantly higher baseline plasma tHcy concentrations in men with the MTHFR 677CT than in those with the 677CC genotype in trial 2. Yet the group size for genotyping was small. Furthermore, in this study almost only 677CT heterozygotes rather than 677T'T homozygotes were compared with 677CC homozygotes. Genetic analyses took place after the study had been performed and with knowledge about the general results of the analyses. Anyhow, the genotype did not modulate any intervention effect. Strengths of this study are the wellcharacterised test material with a closely matched control, the fairly long intervention periods, and the well-documented dietary habits. Potential limitations are variability of dietary habits and thus background diet and further lifestyle factors, including physical activity. Furthermore, only middle-aged overweight male volunteers were included in the studies. In conclusion, under these conditions dietary supplementation with milk-PL as compared with control milk fat reduced waist circumference and, as compared with both control fat and soya-PL, GGT activity.

\section{Acknowledgements}

This work was supported by the Research Association of the German Food Industry (FEI) Germany, project grant AiF-FV 316 ZBG. We thank Lecico for the PL materials, and the Unternehmensgruppe Theo Müller and Milchwerke Mittelelbe 
for preparing the test milks free of charge. The three companies had no role in the design, analysis or writing of this article.

We thank Martina Broßart, Anja Fink, Konstanze Hans, Eva Hoch, Ute Stadler-Prayle and Angelika Thoß for expert technical assistance in this study. We gratefully acknowledge the assistance of Susanne Bandt and Melina Metzig in analysing the 4-d food records. We also thank the participants for their cooperation.

The authors' contributions were as follows: M. P and J. S. designed the study. A. B. was responsible for the screening and medical supervision of the study participants; A. W. and A. B. coordinated the clinical trial; A. W. performed part of the chemical analyses and the statistical analysis; A. W. and M. P. interpreted clinical and laboratory data; S. W. B. established the genotyping technique and supervised the analysis performed by A. W.; M. P. wrote the manuscript and had primary responsibility for the final content. A. W., S. W. B., J. S. and M. P. contributed to the discussion. All authors critically reviewed the manuscript and approved its final version.

None of the authors has any conflict of interest to declare.

\section{References}

1. Lakka HM, Lakka TA, Tuomilehto J, et al. (2002) Abdominal obesity is associated with increased risk of acute coronary events in men. Eur Heart J 23, 706-713.

2. Bastien M, Poirier P, Lemieux I, et al. (2014) Overview of epidemiology and contribution of obesity to cardiovascular disease. Prog Cardiovasc Dis 56, 369-381.

3. Pacifico L, Nobili V, Anania C, et al. (2011) Pediatric nonalcoholic fatty liver disease, metabolic syndrome and cardiovascular risk. World J Gastroenterol 17, 3082-3091.

4. Gaggini M, Morelli M, Buzzigoli E, et al. (2013) Non-alcoholic fatty liver disease (NAFLD) and its connection with insulin resistance, dyslipidemia, atherosclerosis and coronary heart disease. Nutrients 5, 1544-1560

5. Cohn JS, Wat E, Kamili A, et al. (2008) Dietary phospholipids, hepatic lipid metabolism and cardiovascular disease. Curr Opin Lipidol 19, 257-262.

6. Burgess JW, Neville TA, Rouillard P, et al. (2005) Phosphatidylinositol increases HDL-C levels in humans. J Lipid Res 46, 350-355.

7. Polichetti E, Janisson A, Iovanna C, et al. (1998) Stimulation of the apo AI high density lipoprotein system by dietary soyabean lecithin in humans. J Nutr Biochem 9, 659-664.

8. Sanchez-Juanes F, Alonso JM, Zancada L, et al. (2009) Distribution and fatty acid content of phospholipids from bovine milk and bovine milk fat globule membranes. Int Dairy J 19, 273-278.

9. Dewettinck K, Rombaut R, Thienpont N, et al. (2008) Nutritional and technological aspects of milk fat globule membrane material. Int Dairy J 18, 436-457.

10. Eckhardt ER, Wang DQ, Donovan JM, et al. (2002) Dietary sphingomyelin suppresses intestinal cholesterol absorption by decreasing thermodynamic activity of cholesterol monomers. Gastroenterology 122, 948-956.

11. Wat E, Tandy S, Kapera E, et al. (2009) Dietary phospholipid-rich dairy milk extract reduces hepatomegaly, hepatic steatosis and hyperlipidemia in mice fed a high-fat diet. Atherosclerosis 205, 144-150.

12. Watanabe S, Takahashi T, Tanaka L, et al. (2011) The effect of milk polar lipids separated from butter serum on the lipid levels in the liver and the plasma of obese-model mouse $\left(\mathrm{KK}-\mathrm{A}^{\mathrm{y}}\right)$. J Funct Food 3, 313-320.

13. Keller S, Le HY, Rödiger C, et al. (2014) Supplementation of a dairy drink enriched with milk phospholipids in patients with atopic dermatitis - a double-blind, placebo-controlled, randomized, crossover study. Clin Nutr 33, 1010-1016.

14. Ohlsson L, Burling H \& Nilsson A (2009) Long term effects on human plasma lipoproteins of a formulation enriched in butter milk polar lipid. Lipids Health Dis 8, 44.

15. Conway V, Couture P, Richard C, et al. (2013) Impact of buttermilk consumption on plasma lipids and surrogate markers of cholesterol homeostasis in men and women. Nutr Metab Cardiovasc Dis 23, 1255-1262.

16. Baumgartner S, Kelly ER, van der Made S, et al. (2013) The influence of consuming an egg or an egg-yolk buttermilk drink for 12 wk on serum lipids, inflammation, and liver function markers in human volunteers. Nutrition 29, 1237-1244.

17. Rosqvist F, Smedman A, Lindmark-Mansson H, et al. (2015) Potential role of milk fat globule membrane in modulating plasma lipoproteins, gene expression, and cholesterol metabolism in humans: a randomized study. Am I Clin Nutr 102, 20-30.

18. Kullenberg D, Taylor LA, Schneider M, et al. (2012) Health effects of dietary phospholipids. Lipids Health Dis 11, 3.

19. Navder KP, Baraona E \& Lieber CS (1997) Polyenylphosphatidylcholine attenuates alcohol-induced fatty liver and hyperlipemia in rats. J Nutr 127, 1800-1806.

20. Kamili A, Wat E, Chung RW, et al. (2010) Hepatic accumulation of intestinal cholesterol is decreased and fecal cholesterol excretion is increased in mice fed a high-fat diet supplemented with milk phospholipids. Nutr Metab 7, 90

21. Yunoki K, Renaguli M, Kinoshita M, et al. (2010) Dietary sphingolipids ameliorate disorders of lipid metabolism in Zucker fatty rats. J Agric Food Chem 58, 7030-7035.

22. Dobrzyn P, Ntambi JM \& Dobrzyn A (2008) Stearoyl-CoA desaturase: a novel control point of lipid metabolism and insulin sensitivity. Eur J Lipid Sci Technol 110, 93-100.

23. EFSA Panel on Dietetic Products, Nutrition and Allergies (2011) Scientific Opinion on the substantiation of health claims related to choline and contribution to normal lipid metabolism (ID 3186), maintenance of normal liver function (ID 1501), contribution to normal homocysteine metabolism (ID 3090), maintenance of normal neurological function (ID 1502), contribution to normal cognitive function (ID 1502), and brain and neurological development (ID 1503) pursuant to Article 13(1) of Regulation (EC) No 1924/2006. EFS A J 9, 2056.

24. Institute of Medicine (1998) Dietary Reference Intakes for Thiamin, Riboflavin, Niacin, Vitamin $B_{6}$, Folate, Vitamin $B_{12}$, Pantothenic Acid, Biotin, and Choline. Washington, DC: National Academies Press.

25. Fischer LM, daCosta KA, Kwock L, et al. (2007) Sex and menopausal status influence human dietary requirements for the nutrient choline. Am J Clin Nutr 85, 1275-1285.

26. Corbin KD \& Zeisel SH (2012) Choline metabolism provides novel insights into nonalcoholic fatty liver disease and its progression. Curr Opin Gastroenterol 28, 159-165.

27. Solis C, Veenema K, Ivanov AA, et al. (2008) Folate intake at RDA levels is inadequate for Mexican American men with the methylenetetrahydrofolate reductase 677TT genotype. J Nutr 138, 67-72.

28. Veenema K, Solis C, Li R, et al. (2008) Adequate intake levels of choline are sufficient for preventing elevations in serum markers of liver dysfunction in Mexican American men but are not optimal for minimizing plasma total homocysteine increases after a methionine load. Am J Clin Nutr 88, 685-692.

29. Astrup A (2014) Yogurt and dairy product consumption to prevent cardiometabolic diseases: epidemiologic and experimental studies. Am J Clin Nutr 99, 1235s-1242s.

30. Ingelsson E, Schaefer EJ, Contois JH, et al. (2007) Clinical utility of different lipid measures for prediction of coronary heart disease in men and women. JAMA 298, 776-785.

31. Koebnick C, Wagner K, Thielecke F, et al. (2005) An easy-to-use semiquantitative food record validated for energy intake by using doubly labelled water technique. Eur J Clin Nutr 59, 989-995.

32. World Health Organization (2008) Guide to Physical Measurements Step 2. http://www.who.int/chp/steps/Part3_Section3.pdf (accessed March 2010). 
33. Becker K, Gui M, Traxler A, et al. (1994) Redox processes in malaria and other parasitic diseases. Determination of intracellular glutathione. Histochemistry 102, 389-395.

34. Toyo'oka T \& Imai K (1983) High-performance liquid chromatography and fluorometric detection of biologically important thiols, derivatized with ammonium 7-fluorobenzo-2-oxa-1,3-diazole-4sulphonate (SBD-F). J Chromatogr 282, 495-500.

35. Matthews DR, Hosker JP, Rudenski AS, et al. (1985) Homeostasis model assessment: insulin resistance and $\beta$-cell function from fasting plasma glucose and insulin concentrations in man. Diabetologia 28, 412-419.

36. Goyens PL \& Mensink RP (2005) The dietary $\alpha$-linolenic acid to linoleic acid ratio does not affect the serum lipoprotein profile in humans. J Nutr 135, 2799-2804.

37. Yonemori KM, Lim U, Koga KR, et al. (2013) Dietary choline and betaine intakes vary in an adult multiethnic population. J Nutr 143, 894-899.

38. Ramprasath VR, Jones PJ, Buckley DD, et al. (2013) Effect of dietary sphingomyelin on absorption and fractional synthetic rate of cholesterol and serum lipid profile in humans. Lipids Health Dis 12, 125.

39. Kesaniemi YA \& Grundy SM (1986) Effects of dietary polyenylphosphatidylcholine on metabolism of cholesterol and triglycerides in hypertriglyceridemic patients. Am J Clin Nutr 43, 98-107.
40. Conway V, Gauthier SF \& Pouliot Y (2010) Effect of cream pasteurization, microfiltration and enzymatic proteolysis on in vitro cholesterol-lowering activity of buttermilk solids. Dairy Sci Tecbnol 90, 449-460.

41. Bourlieu C \& Michalski MC (2015) Structure-function relationship of the milk fat globule. Curr Opin Clin Nutr Metab Care 18, 118-127.

42. Shiby VK \& Mishra HN (2013) Fermented milks and milk products as functional foods - a review. Crit Rev Food Sci Nutr 53, 482-496.

43. Conway V, Couture P, Gauthier S, et al. (2014) Effect of buttermilk consumption on blood pressure in moderately hypercholesterolemic men and women. Nutrition 30, 116-119.

44. Tremblay A \& Gilbert JA (2011) Human obesity: is insufficient calcium/dairy intake part of the problem? J Am Coll Nutr 30, 449s-453s.

45. Bendtsen LQ, Lorenzen JK, Larsen TM, et al. (2014) Associations between dairy protein intake and body weight and risk markers of diabetes and CVD during weight maintenance. Br J Nutr 111, 944-953.

46. Detopoulou P, Panagiotakos DB, Antonopoulou S, et al. (2008) Dietary choline and betaine intakes in relation to concentrations of inflammatory markers in healthy adults: the ATTICA study. Am J Clin Nutr 87, 424-430. 